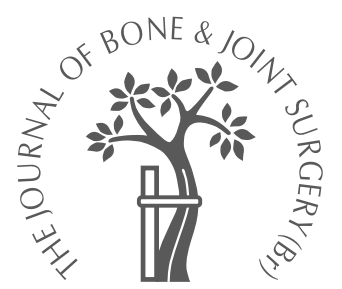

C. A. Goldfarb, W. M. Ricci, F. Tull, D. Ray, J. Borrelli Jr

From Barnes-Jewish Hospital, St Louis, Missouri, USA

\title{
Functional outcome after fracture of both bones of the forearm
}

Our aim was to correlate the health status with objective and radiological outcomes in patients treated by open reduction and internal fixation for fractures of both bones of the forearm.

We assessed 23 patients (24 fractures) subjectively, objectively and radiologically at a mean of 34 months (11 to 72). Subjective assessment used the disability of the arm, shoulder and hand (DASH) and musculoskeletal functional attachment (MFA) questionnaires. The range of movement of the forearm and wrist, grip and pinch strength were measured objectively and standardised radiographs were evaluated.

In general, patients reported good overall function based on the DASH (mean 12; range 0 to 42) and MFA (mean 19; range 0 to 51) scores. However, pronation and grip and pinch strength were significantly decreased $(p<0.005)$. These deficiencies correlated with poorer subjective outcomes.

Operative stabilisation of fractures of the radius and ulna led to a reliably acceptable functional outcome. However, despite these generally satisfactory results, the outcome scores worsened with reduction in the range of movement of the forearm and wrist.

Fractures of both bones of the forearm are relatively common injuries which can challenge the treating physician. ${ }^{1-16}$ Healing occurs reliably after closed treatment but malunion, with resultant decreased rotation of the forearm, is common and has been associated with poor results. ${ }^{17,18}$ Rotation of the forearm is a complex interaction between the radius and ulna and the restoration of this movement depends on both an accurate reduction of the fractures and early initiation of post-operative movement. ${ }^{1-24}$ Loss of rotation impedes function of the upper limb and activities of daily living. Multiple investigations, using similar objective and radiological outcome measures, have documented high rates of healing of the fractures and the restoration of a satisfactory arc of rotation of the forearm..$^{3-6,10,11,25,26}$ These findings have been used to justify open reduction and plate fixation of such fractures. While some authors ${ }^{23-26}$ have demonstrated the importance of restoration of the radial bow in achieving maximal rotation, the use of subjective functional outcome measures has not been documented.

Validated functional outcome instruments are used to evaluate a patient's perceptions of their recovery from musculoskeletal injuries, ${ }^{27-32}$ but there have been no investiga- tions using these instruments to assess the outcome in patients after treatment for fractures of both bones of the forearm. We have therefore evaluated the outcome of patients treated by open reduction and internal fixation (ORIF) for such injuries by comparing subjective, validated outcome measures with the more commonly used objective measures.

\section{Patients and Methods}

We identified all patients treated surgically for fracture of both bones of the forearm between May 1996 and October 2001. Those who had been treated by ORIF within one week of injury by the senior author (JB), were eligible for inclusion. Twenty-eight patients were identified and 23 (24 fractures) were willing to return for follow-up studies. Of the five patients who did not return for follow-up, three could not be located, one refused participation and one had died. A clinical nurse (DR), not involved in the care of these patients, obtained the subjective and objective data at the time of their most recent follow-up. Our institutional review board approved this investigation and informed consent was obtained from all patients before participation in the study. 
Table I. Details of the 23 patients

\begin{tabular}{|c|c|c|c|c|c|c|c|c|c|}
\hline Case & $\begin{array}{l}\text { Age } \\
\text { (yrs) }\end{array}$ & Gender & $\begin{array}{l}\text { Injured } \\
\text { side* }^{*}\end{array}$ & $\begin{array}{l}\text { Dominant } \\
\text { side* }^{*}\end{array}$ & $\begin{array}{l}\text { Duration of } \\
\text { follow-up } \\
\text { (mths) }\end{array}$ & Occupation & Associated injuries & $\begin{array}{l}\text { Mechanism } \\
\text { of injury }\end{array}$ & $\begin{array}{l}\text { AO fracture } \\
\text { classification }\end{array}$ \\
\hline 1 & 43 & $M$ & $\mathrm{~L}$ & $\mathrm{R}$ & 23 & Police officer & None & Fall & $22-A 3.2$ \\
\hline 2 & 54 & $\mathrm{~F}$ & $\mathrm{~L}$ & $\mathrm{R}$ & 25 & Housewife & None & Fall & 22-A3.2 \\
\hline 3 & 31 & $\mathrm{~F}$ & $\mathrm{R}$ & $\mathrm{L}$ & 22 & Nurse & None & MVAł & 22-A3.2 \\
\hline 4 & 38 & $\mathrm{~F}$ & $\mathrm{~L}$ & $\mathrm{R}$ & 12 & Factory supervisor & None & Work injury & 22-A3.3 \\
\hline 5 & 28 & M & $\mathrm{L}$ & $\mathrm{R}$ & 17 & Police officer & $\mathrm{Fx}^{\dagger}$, tibia, fibula, tibial plateau, acetabulum & MVA & 22-B3.3 \\
\hline 6 & 29 & M & $\mathrm{L}$ & $\mathrm{R}$ & 48 & Machinist & Fx, femoral shaft, tibia, fibula & MVA & 22-A3.3 \\
\hline 7 & 58 & $\mathrm{~F}$ & $\mathrm{R}$ & $\mathrm{R}$ & 23 & Housewife & None & MVA & $22-\mathrm{C} 3.2$ \\
\hline 8 & 26 & M & $\mathrm{R}$ & $\mathrm{R}$ & 30 & Cook & None & MVA & 22-A3.2 \\
\hline 9 & 44 & M & $\mathrm{R}$ & $\mathrm{R}$ & 31 & Machine operator & None & Work injury & 22-A3.1 \\
\hline 10 & 56 & M & $\mathrm{R}$ & $\mathrm{R}$ & 68 & Installer & None & Work injury & 22-A3.1 \\
\hline 11 & 44 & M & $\mathrm{R}$ & $\mathrm{R}$ & 55 & Labourer & None & MVA & $22-\mathrm{C} 3.1$ \\
\hline 12 & 26 & M & $\mathrm{L}$ & $\mathrm{R}$ & 29 & Construction & Rotator-cuff tear/biceps dislocation & MVA & 22-A3.3 \\
\hline 13 & 36 & M & $\mathrm{L}$ & $\mathrm{R}$ & 44 & Unemployed & None & Work injury & 22-A3.2 \\
\hline 14 & 35 & $\mathrm{~F}$ & $\mathrm{R}$ & $\mathrm{L}$ & 72 & Machine operator & None & Fall & 22-A3.2 \\
\hline 15 & 21 & $\mathrm{~F}$ & $\mathrm{~L}$ & $\mathrm{R}$ & 37 & Student & None & MVA & 22-A3.2 \\
\hline 16 & 47 & M & $\mathrm{L}$ & $\mathrm{R}$ & 47 & Factory assembler & None & MVA & 22-A3.2 \\
\hline 17 & 84 & $\mathrm{~F}$ & $\mathrm{R}$ & $\mathrm{R}$ & 28 & Retired & None & Fall & 22-A3.3 \\
\hline 18 & 55 & $\mathrm{~F}$ & $\mathrm{R}$ & $\mathrm{R}$ & 18 & Unemployed & None & MVA & 22-C3.1 \\
\hline 19 & 37 & $\mathrm{~F}$ & $\mathrm{~L}$ & $\mathrm{R}$ & 48 & Unemployed & Fx, facial, pelvis, abdominal injuries & $\begin{array}{l}\text { Pedestrian } \\
v s \text { train }\end{array}$ & 22-B3.1 \\
\hline 20 & 42 & M & $\mathrm{L}$ & $\mathrm{R}$ & 11 & Cook & Fx, tibial plateau, lateral meniscal tear & MVA & 22-A3.2 \\
\hline \multirow[t]{2}{*}{21} & 26 & M & $\mathrm{R}$ & $\mathrm{R}$ & 18 & Mechanic & None & MVA & 22-B3.2 \\
\hline & 26 & M & $\mathrm{L}$ & $\mathrm{R}$ & 18 & Mechanic & None & MVA & 22-A3.2 \\
\hline 22 & 23 & M & $\mathrm{L}$ & $\mathrm{R}$ & 53 & Student & None & Fall & 22-A3.1 \\
\hline 23 & 19 & M & $\mathrm{R}$ & $\mathrm{R}$ & 20 & Student & $\begin{array}{l}\text { Fx, femur/patella, L glenoid, pneumothorax, } \\
\text { aortic transection, kidney laceration }\end{array}$ & MVA & 22-A3.1 \\
\hline
\end{tabular}

* L, left; $R$, right

† FX, fracture

‡ motor-vehicle accident

There were 14 men and nine women with a mean age of 40 years (19 to 84 ). The mean time to follow-up was 34 months (11 to 72). There were nine fractures of the dominant and 15 of the non-dominant limb. Eighteen were closed and six were type-I open fractures. ${ }^{33}$ There were neither concomitant injuries nor a history of previous fractures nor abnormalities of the affected limb. Six patients had associated musculoskeletal injuries. Two had fractures of the contralateral upper limb, three had a fracture of the tibia, two had a fracture of the pelvis and two had abdominal injuries (Table I).

The mechanism of injury was a motor-vehicle accident in 13 patients, a fall from a height in five, a work-related injury in four and a pedestrian $v$ s train accident in one. At the time of injury, 14 patients were employed outside of the home, four were unemployed, three were full-time students, and two were housewives. Four patients were treated under worker's compensation and five other patients were involved in litigation.

All patients were initially treated in the emergency department by closed reduction and application of a longarm splint. Six with open injuries received urgent irrigation and debridement, immediate ORIF and primary wound closure. The other 18 fractures were treated operatively at a mean of two days ( 0 to 7 ) after injury. In each case, the ulna was approached along its subcutaneous border and the radius was exposed through a volar Henry approach with preservation of the insertion of pronator teres. ${ }^{34}$ All frac- tures were stabilised by $3.5 \mathrm{~mm}$ dynamic compression plates (Synthes USA, Paoli, Pennsylvania). Bone grafting was not performed.

Post-operatively, long-arm splints were applied with the elbow flexed to $90^{\circ}$ and the forearm in neutral rotation for a mean of eight days (6 to 14). After removal of the splint the patients were instructed in active, and active-assisted, range of movement of the upper limb. Formal physiotherapy, with therapist-assisted range-of-movement and muscle-strengthening exercises, began six weeks after operation.

Routine radiographs were taken at two, six and 12 weeks and then, usually, at intervals of two to three months until healing was confirmed. There were no complications and no cases of delayed union or nonunion. Additional surgery was not required.

Subjective follow-up evaluation. We used two validated, selfadministered questionnaires for the assessment of musculoskeletal function, the musculoskeletal function assessment (MFA) $)^{35-37}$ and the disabilities of the arm, shoulder and hand (DASH) $)^{29,35-41}$ scores.

The MFA is a 100-item, self-administered questionnaire on health status intended to assess self-perceptions of physical status, psychological status and the social well-being of patients who have disorders of the upper or lower limbs. Studies have shown that this instrument has good reliability, good criterion and good construct validity. ${ }^{35-38}$ Specific functional domains assessed by the MFA include self-care, 


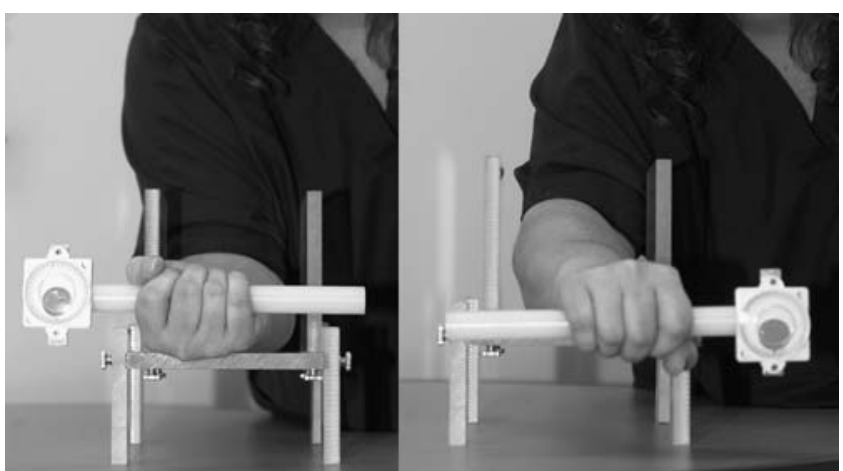

Fig. 1a

Fig. 1b

Photographs showing standardised measurement of a) supination and b) pronation of the forearm.

sleep and rest, hand and fine motor skills, mobility, housework, employment and work activities, leisure and recreational activities, family relationships, cognition and thinking, and emotional adjustment. A low score indicates that the patient perceives minimal problems with function, while a high score indicates a greater perception of a problem. The questionnaire provides a summary score as well as a separate score for each domain. The outcome measures used in our study included the total score and the score for the hand and fine motor skills domain.

The DASH is a 30-item questionnaire intended to assess the function and symptoms of persons with disorders of the upper limb. ${ }^{29,37,39-41}$ Patients rate their ability to perform 21 physical activities such as opening jars, turning doorknobs and similar activities. The remaining nine items relate to symptoms (six items) and self-image and social life (three items). Each is scored on a five-point Likert scale.
The raw score is converted to a global score ranging from 0 to 100 . A score of 0 indicates 'no disability', and 100 indicates 'severe disability'.

Objective follow-up. Rotation of the forearm was assessed with the elbow flexed to $90^{\circ}$ and the arm adducted. It was measured by a hand-held, level-like device which the patient clasped while rotating their forearm (Fig. 1). Extension and flexion of the wrist were measured by a goniometer placed along the ulnar border of the forearm and hand. The contralateral, unaffected forearm and wrist were used as controls for each measurement. In the patient with bilateral fractures of the radius and ulna, the mean range of movement of the unaffected limbs of the other patients was used as the control value.

Grip strength was assessed by the Jamar dynamometer (Asimov Engineering, Los Angeles, California) and lateral pinch strength by a pinch meter (Therapeutic Instruments, Clifton, New Jersey). Strength was assessed in a standard fashion and the mean of three trials for both grip and lateral pinch strength was used.

Imaging evaluation. Standard AP and lateral radiographs of the forearm were taken at the time of injury and were used to classify each fracture according to the comprehensive classification of fractures. ${ }^{42}$ There were 18 22-A, three 22-B and three 22-C fractures (Table I; Fig. 2).

Standard radiographs taken at the time of final follow-up were evaluated in a blinded fashion by an independent observer. The amount and location of the maximal radial bow were determined according to the technique described by Schemitsch and Richards. ${ }^{23}$

Statistical analysis. The data were analysed by the SAS programme (SAS Institute, Cary, North Carolina). Testing for significance was performed by the $t$-test for paired continuous variables. The level of significance was $p \leq 0.05$ and the Wilcoxon signed-rank probability test was used.
22- Radius/Ulna diaphysis

22-A Simple fracture

A1
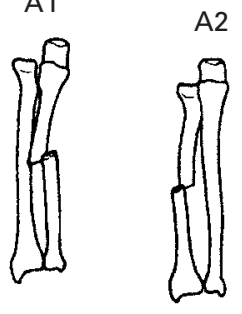

22-A1 of ulna, radius intact

22-A2 of radius, ulna intact

22-A3 of both bones
22-B Wedge fracture

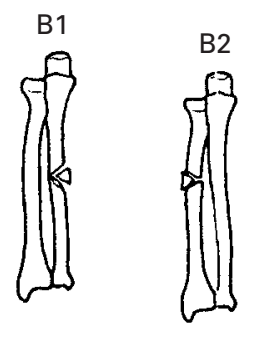

22-B1

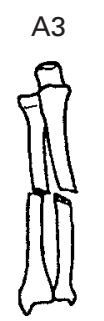

22-B2

22-B3$$
\begin{aligned}
& 22-\mathrm{B} 2 \\
& 22-\mathrm{B} 3
\end{aligned}
$$

of ulna, radius intact

of radius, ulna intact

of one bone wedge, the other simple or wedge
22-C Complex fracture

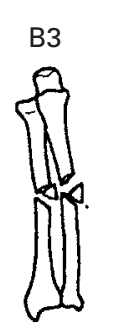

22-C1

22-C2

of radius

22-C3 of both bones

Fig. 2 
Table II. Objective outcomes including range of movement of the wrist and forearm, grip and lateral pinch strength (involved/uninvolved), MRB ${ }^{*}$ and $\mathrm{LMRB}^{\dagger}$

\begin{tabular}{|c|c|c|c|c|c|c|c|c|}
\hline & $\begin{array}{l}\text { Wrist } \\
\text { flexion ( }\end{array}$ & $\begin{array}{l}\text { Wrist } \\
\text { extension }\left({ }^{\circ}\right)\end{array}$ & $\begin{array}{l}\text { Forearm } \\
\text { pronation }\left({ }^{\circ}\right)\end{array}$ & $\begin{array}{l}\text { Forearm } \\
\text { supination } \\
\left({ }^{\circ}\right)\end{array}$ & $\begin{array}{l}\text { Grip } \\
\text { (kg) }\end{array}$ & $\begin{array}{l}\text { Pinch } \\
\text { (kg) }\end{array}$ & $\begin{array}{l}\text { MRB* } \\
(\mathrm{mm})\end{array}$ & $\begin{array}{l}\text { LMRB† } \\
(\%)\end{array}$ \\
\hline Mean & $65 / 70$ & $65 / 70$ & $75 / 85$ & $85 / 95$ & $34 / 40$ & $21 / 23$ & 16 & 62 \\
\hline Range & 40 to 85 & 35 to 95 & 10 to 60 & 0 to 125 & 12 to 68 & 11 to 33 & 10 to 20 & 42 to 70 \\
\hline
\end{tabular}

* MRB, maximal radial bow

† LMRB, location of maximal radial bow

\section{Results}

The mean total MFA score was $19 \pm 17$ (0 to 51 ). The two domains with the highest scores (suggesting poorest function) were mobility $(5 \pm 4)$ and coping $(5 \pm 4)$. The hand and fine motor domain scores $(1 \pm 1)$ and cognition score (1 \pm 1 ) had the lowest domain scores (best function). The mean scores for the other six domains was between 1 and 2 .

The mean DASH score was $12 \pm 10$ (0 to 42 ). A strongly positive correlation was noted between the total MFA score and the DASH score $(\mathrm{r}=0.82, \mathrm{p} \leq 0.01)$.

There were eight patients with an MFA score above 20 and only one of these patients was treated under worker's compensation or was involved in litigation. There were nine patients with a DASH score above 12 and only two were treated under workman's compensation or were involved in litigation. Of the remaining eight patients, there were two police officers, one labourer, one factory assembler, one retiree, one cook, one mechanic and one unemployed person. Five patients had additional, significant injuries, excluding one (case 12) with a tear of the rotator cuff. Three of these patients had an MFA score above 20 and two had a DASH score above 12 .

The mean $( \pm \mathrm{SD})$ pronation for the involved and uninvolved sides was $75 \pm 25^{\circ}$ and $85 \pm 25^{\circ}$, respectively and the mean supination $85 \pm 30^{\circ}$ and $95 \pm 15^{\circ}$, respectively (Table II). The difference in pronation between the injured and uninjured sides was statistically significant $(\mathrm{p}=0.005)$, while the difference in supination was not $(p=0.11)$. Six patients lost more than $20 \%$ of their arc of rotation and six between $10 \%$ and $20 \%$ of rotation. Two patients did not maintain a functional arc of pronation and supination $\left(50^{\circ}\right.$ pronation $/ 50^{\circ}$ supination) while two others failed to maintain a functional arc of pronation or supination. Worsening DASH scores correlated with worsening subjective function in those patients with decreased pronation of the forearm $(\mathrm{p}<0.05)$.

The mean extension of the wrist for the involved and uninvolved sides was $65 \pm 10^{\circ}$ and $70 \pm 15^{\circ}$, respectively and the mean flexion $65 \pm 15^{\circ}$ and $70 \pm 10^{\circ}$, respectively (Table II). The difference in extension and flexion of the wrist between the injured and uninjured sides was not statistically significant ( $p>0.05$ and $\mathrm{p}=0.06$, respectively). Five patients lost more than $20 \%$ of their arc of either flexion or extension; no patient lost more than $10 \%$ of both. All patients maintained a functional arc of movement of the wrist $\left(10^{\circ}\right.$ extension and $30^{\circ}$ flexion).
Both the DASH and the MFA showed worse outcomes in patients with a decreased range of movement of the forearm and wrist. Inverse correlations were observed between the MFA and flexion and extension of the wrist. The total MFA score was inversely correlated with flexion of the wrist $(r=-0.51, p \leq 0.05)$, but was not correlated with extension $(\mathrm{r}=-0.41, \mathrm{p} \leq 0.10)$. Additionally, worsening DASH scores correlated with decreased supination $(\mathrm{r}=$ $-0.47, \mathrm{p} \leq 0.05)$, pronation $(\mathrm{r}=-0.66, \mathrm{p} \leq 0.01)$ and flexion $(\mathrm{r}=-0.64, \mathrm{p} \leq 0.01)$ and extension of the wrist $(\mathrm{r}=-0.46, \mathrm{p}$ $\leq 0.05)$.

The mean grip strength for the involved and uninvolved sides was $34 \pm 15 \mathrm{~kg}$ and $40 \pm 15 \mathrm{~kg}$, respectively (Table II). The difference between the injured and uninjured sides was statistically significant $(p=0.0004)$. The mean lateral key pinch strength, for the involved and uninvolved sides was $21 \pm 5 \mathrm{~kg}$ and $23 \pm 10 \mathrm{~kg}$, respectively (Table II). The difference between the injured and uninjured sides was also statistically significant $(\mathrm{p}=0.02)$ (Table II). Surprisingly, neither pinch nor grip strength correlated with the DASH or MFA scores. As would be expected, however, pinch strength was strongly correlated with grip strength $(\mathrm{r}=$ $0.58, \mathrm{p} \leq 0.001$ ).

Alignment of the radius was assessed by the maximal radial bow and its location and the results were compared with normative values established by Schemitsch and Richards $^{23}$ (mean maximal radial bow $15.3 \mathrm{~mm}$; mean location $59.9 \%$ ). The mean maximal radial bow in our patients after fixation of the fracture was $16 \pm 3 \mathrm{~mm}$ (10 to 20 ) and its mean location $62 \pm 8 \%$ (42 to 70 ) (Table II).

A thorough evaluation of the relationship between movement of the forearm and the radiological parameters showed that patients with a loss of the arc of rotation of less than $10 \%$ had a mean difference of $1.9 \mathrm{~mm} \mathrm{(12 \% )} \mathrm{from} \mathrm{the}$ normal maximal radial bow, and of $6.7 \%$ from the normal location of the maximal radial bow. Those patients with a loss of rotation of $10 \%$ to $20 \%$ had a mean difference of $2.0 \mathrm{~mm} \mathrm{(13 \% )} \mathrm{from} \mathrm{the} \mathrm{normal} \mathrm{maximal} \mathrm{radial} \mathrm{bow,} \mathrm{and}$ of $6 \%$ from the normal location of the maximal radial bow, while those with a loss of rotation of more than $20 \%$ had a mean difference of $2.3 \mathrm{~mm} \mathrm{(15 \% )}$ ) from the normal maximal radial bow, and of $6.5 \%$ from the normal location of the maximal radial bow.

As previously undertaken by Schemitsch and Richards, ${ }^{23}$ we compared the six patients in our series with forearm rotation of less than $80 \%$ with the other 17 patients with 
forearm rotation of more than $80 \%$. We were unable to demonstrate a significant difference between the groups concerning rotation and either maximal radial bow or location of the maximal radial bow $(\mathrm{p}=0.40$ and 0.19 , respectively). Statistical analysis showed that as the difference from the normal maximal radial bow increased, regardless of whether it was greater or less than normal, supination of the injured limb also increased $(r=0.53, p=0.01)$.

\section{Discussion}

Compression plate fixation has become the treatment of choice for fractures of both bones of the forearm. ${ }^{16,17,43}$ Compression plate fixation gives a high rate of union, a low rate of complications, and a satisfactory return of rotation of the forearm. 1,10,11 However, while the objective and radiological data support the use of compression plating for such fractures, validated subjective data have been lacking. We sought to address this deficit by the use of two validated outcome instruments, the DASH and the MFA.

The results of our study are consistent with the clinical and radiological results of previous studies of ORIF of fracture of both the radius and ulna..$^{8-10,24,25,35}$ Compression plating, with an attempt to restore the pre-injury anatomy of the forearm, led to satisfactory movement of the forearm and muscle strength. While subjective patient outcomes were also generally good, an assessment of the objective data with reference to the outcome scores has provided additional information.

While the range of movement was decreased in most patients at the final follow-up, only pronation showed a statistically significant reduction compared with the contralateral limb. However, the outcomes questionnaires found a subjective decrease in function when the range of movement of the wrist and forearm was less than that of the uninjured side. This suggests that any decrease in movement of the forearm or wrist must be carefully noted since it may affect the patients' perception of their functional outcome. By contrast, decreasing grip and pinch strength were not found to correlate with outcome scores suggesting that while these decreases may be statistically significant they are not clinically significant.

The MFA and the DASH were strongly correlated suggesting that function of the upper limb may be sufficiently assessed by a general health questionnaire such as the MFA. However, differences in the two measurements were noted which confirms a role for each questionnaire. For example, the MFA score showed a significant correlation with range of movement of the wrist, while the DASH score correlated with range of movement of both the forearm and wrist. The higher sensitivity of the DASH to decreasing movement of the forearm suggests that this instrument may be more useful than the MFA when evaluating function of the upper limb.

Schemitsch and Richards ${ }^{23}$ showed that the restoration of forearm bow, as assessed by the maximal radial bow and its location, is crucial for the return of rotation. They found that patients with return of forearm movement of at least $80 \%$, compared with those with less than $80 \%$, had more anatomical healing of the radius as assessed by the maximal radial bow and its location. While the values for the maximal radial bow and its location in our patients were similar to the normative values established by Schemitsch and Richards, ${ }^{23}$ we were unable to reproduce the close correlation between the range of movement of the forearm and the restoration of the radial bow. We found no significant difference in the maximal radial bow or its location in patients with movement of the forearm of greater than or less than $80 \%$.

Pronation and supination of the forearm and flexion and extension of the wrist were specifically assessed for their relationship to the maximal radial bow and its location. While pronation and the arc of movement of the wrist were both significantly reduced $(\mathrm{p}<0.05)$ in our patients, neither correlated with the maximal radial bow or its location. The arc of supination, which was not significantly reduced $(\mathrm{p}>$ 0.05 ) at the final follow-up, did correlate with the maximal radial bow. Our data do not minimise the importance of an anatomical reduction during fixation by a compression plate, but they do suggest that other factors may also be important for the restoration of the arc of movement of the forearm. We currently emphasise the use of early active and passive movement of the forearm and wrist in an attempt to maximise post-operative function.

The DASH score for our patients was considerably better than that of patients with long-standing problems of the shoulder or wrist. In the study by Beaton et $\mathrm{al}^{39}$ to validate use of the DASH score, patients with shoulder problems had a mean score of $48.4 \pm 21.2$, while those with isolated problems of the wrist had a mean score of $34.2 \pm 23.69$ before treatment. Although the MFA scores of our patients (mean of $20 \pm 17$ ) were considerably higher than previously published norms for non-patient groups (mean of $9.26 \pm$ $8.9)^{43}$ they were approximately equal to the 75 th percentile (17.33) in the previously published study on the AO/OTA group with elbow, forearm and hand injury at 12 months after injury. ${ }^{43}$

The primary limitation of this investigation is the small number of patients. However, we feel that this was mitigated by two factors. First, we presented a homogeneous group of patients treated by a single surgeon in a standard fashion and, secondly, there was a high percentage of eligible patient participation with a follow-up for more than one year. A second weakness of our investigation was our technique of assessment of forearm rotation. The method used included the assessment of rotation of the wrist and forearm. However, we were consistent and we measured the contralateral, uninjured limb in a similar fashion. Therefore, this limits our data only in the fact that our measurements of forearm rotation may not be comparable with those of other investigations.

Anatomical reduction and stable internal fixation should continue to be the standard methods of treatment for frac- 
tures of both bones of the forearm in adults. In order to maximise the patients' perception of outcome, attention should be paid to the return of normal movement of the forearm and wrist. The patients' view of function as determined by the DASH questionnaire was dependent on the return of rotation of the forearm and range of movement of the wrist whereas outcome based upon the MFA correlated only with movement of the wrist. The DASH outcome measure is more sensitive than the MFA when assessing outcome after ORIF of such fractures.

No benefits in any form have been received or will be received from a commer cial party related directly or indirectly to the subject of this article.

\section{References}

1. Dodge H, Cady G. Treatment of fractures of the radius and ulna with compression plates. J Bone Joint Surg [Am] 1972;54-A:1167-76.

2. Kasser J. Forearm fractures. Instr Course Lect 1992;41:391-6.

3. McAuliffe JA. Forearm fixation. Hand Clinics 1997;13:689-701.

4. Duncan R, Geisller W, Freeland A, Savoie F. Immediate internal fixation of open fractures of the diaphysis of the forearm. J Orthop Trauma 1992;6:25-31.

5. Hertel R, Pisan M, Lambert S, Ballmer F. Plate osteosynthesis of diaphyseal fractures of the radius and ulna. Injury 1996;27:545-8.

6. Roy D, Crawford A. Operative management of fractures of the shaft of the radius and ulna. Orthop Clinic North Am 1990;21:245-50

7. Langkamer V, Ackroyd C. Internal fixation of forearm fractures in the 1980's: lessons to be learnt. Injury 1991;5:272-9.

8. Ross E, Gourevitch D, Hastings G, Wynn-Jones C, Ali S. Retrospective analysis of plate fixation of diaphyseal fractures of the forearm bones. Injury 1989:20:211-14.

9. Hadden W, Reschauer R, Seggl W. Results of $A O$ plate fixation of forearm shaft fractures in adults. Injury 1983;15:44-52.

10. Chapman M, Gordon E, Zissimos A. Compression-plate fixation of acute fractures of the diaphyses of the radius and ulna. J Bone Joint Surg [Am] 1989;71-A:159-69.

11. Anderson LD, Sisk D, Tooms RE, Park WI III. Compression-plate fixation in acute diaphyseal fractures of the radius and ulna. J Bone Joint Surg [Am] 1975;57-A: 287-97.

12. Moed BR, Kellam JF, Foster RJ, Tile M, Hansen ST Jr. Immediate internal fixation of open fractures of the diaphysis of the forearm. J Bone Joint Surg [Am]1986; 68-A:1008-17.

13. Knight RA, Purvis GD. Fractures of both bones of the forearm in adults. J Bone Joint Surg [Am] 1949;31-A:755-64.

14. Burwell HN, Charnley AD. Treatment of forearm fractures in adults with particular reference to plate fixation. J Bone Joint Surg [Br] 1964;46-B:404-25.

15. Sargent JP, Teipner WA. Treatment of forearm shaft fractures by double-plating: a preliminary report. J Bone Joint Surg [Am] 1965;47-A:1475-90.

16. Smith JEM. Internal fixation in the treatment of fractures of the shafts of the radius and ulna in adults: the value of delayed operation in the prevention of non-union J Bone Joint Surg [Br] 1959;41-B:122-31.

17. Matthews LS, Kaufner H, Garver DF, Sonstegard DA. The effect on supinationpronation of angular malalignment of fractures of both bones of the forearm. $J$ Bone Joint Surg [Am] 1982;64-A:14-17.

18. Tarr RR, Garfinkel Al, Sarmiento A. The effects of angular and rotational deformities of both bones of the forearm: an in vitro study. J Bone Joint Surg [Am] 1984; 66-A:65-70

19. Jupiter JB, Kour AK, Richards RR, Nathan J, Meinhard B. The floating radius in bipolar fracture-dislocation of the forearm. J Orthop Trauma 1994;8:99-106.

20. Patterson B. Forearm fractures: open reduction internal fixation. In: Wiss $D$, ed Master techniques in orthopaedic surgery: fractures. Vol. 10. Philadelphia: LippincottRaven Publishers, 1998:143-53.
21. Tynan MC, Fornalski S, McMahon PJ, et al. The effects of ulnar axial malalignment on supination and pronation. J Bone Joint Surg [Am]2000;82-A:1726-31.

22. Grace T, Eversmann WW Jr. Forearm fractures: treatment by rigid fixation with early motion. J Bone Joint Surg [Am] 1980;62-A:433-9.

23. Schemitsch $\mathbf{E}$, Richards $\mathbf{R}$. The effect of malunion on functional outcome after plate fixation of fractures of both bones of the forearm in adults. J Bone Joint Surg [Am] 1992;74-A:1068-78.

24. Schemitsch EH, Jones D, Henley MB, Tencer AF. A comparison of malreduction after plate and intramedullary nail fixation of forearm fractures. J Orthop Trauma 1995;9:8-16.

25. Wilson F, DirschI D, Bynum D. Fractures of the radius and ulna in adults: an analysis of factors affecting outcome. lowa Orthop J 1997;17:14-19.

26. McHenry TP, Pierce WA, Lais RL, Schacherer TG. Effect of displacement of ulna-shaft fractures on forearm rotation: a cadaveric model. Am J Orthop 2002:31: 420-4

27. Catalano LW 3rd, Cole R, Gelberman R, et al. Displaced intra-articular fractures of the distal aspect of the radius: long-term results in young adults after open reduction and internal fixation. J Bone Joint Surg [Am]1997;79-A:1290-302

28. Ring D, Perey B, Jupiter JB. The functional outcome of operative treatment of ununited fractures of the humeral diaphysis in older patients. J Bone Joint Surg [Am] 1999:81-A:177-90.

29. Navsarikar A, Gladman D, Husted J, Cook R. Validity assessment of the disabilities of arm, shoulder and hand questionnaire (DASH) for patients with psoriatic arthritis. J Rheumato/ 1999;26:2191-4

30. Yokoyama K, Itoman M, Kobayashi A, Shindo M, Futami T. Functional outcomes of "floating elbow" injuries in adult patients. J Orthop Trauma 1998;12:284-90.

31. Fernandez J, Gruen G, Herndon JH. Outcome of distal radius fractures using the short form 36 health survey. Clin Orthop 1997;341:36-41

32. McKee MD, Kim J, Kebaish K, et al. Functional outcome after open supracondylar fractures of the humerus: the effect of the surgical approach. J Bone Joint Surg $[\mathrm{Br}]$ 2000;82-B:646-51.

33. Gustilo RB, Anderson JT. Prevention of infection in the treatment of one thousand and twenty-five open fractures of long bones: retrospective and prospective analyses. J Bone Joint Surg [Am] 1976;58-A:453-8.

34. Henry A. Extensile exposure applied to limb surgery. Second ed. Edinburgh: Churchill Livingstone 1973:100-6.

35. Swiontkowski M, Engelberg R, Martin D, Agel J. Short musculoskeletal function assessment questionnaire: validity, reliability, and responsiveness. J Bone Joint Surg [Am] 1999:81-A:1245-60.

36. Martin DP, Engelberg R, Agel J, Snapp D, Swiontkowski MF. Development of a musculoskeletal extremity health status instrument: the musculoskeletal function assessment instrument. J Orthop Res 1996;14:173-81.

37. Engelberg R, Martin DP, Agel J, et al. Musculoskeletal function assessment instrument: criterion and construct validity. J Orthop Res 1996;14:182-92.

38. Soohoo N, McDonald AP, Seiler JG rd, McGillivary GR. Evaluation of the construct validity of the DASH questionnaire by correlation to the SF-36. J Hand Surg [Am]2002;27:537-41.

39. Beaton DE, Katz JN, Fossel AH, et al. Measuring the whole or the parts? Validity reliability, and responsiveness of the disabilities of the arm, shoulder and hand outcome measure in different regions of the upper extremity. J Hand Ther 2001;14 $128-46$

40. Beaton DE, Davis AM, Hudak PL, McConnell HP. The DASH (disabilities of the arm, shoulder and hand) outcome measures: what do we know about it now? Br J Hand Ther 2001;6:109-18.

41. Hudak PL, Amadio PC, Bombardier C. Development of an upper extremity out come measure: the DASH (disabilities of the arm, shoulder and hand): the Upper Extremity Collaborative Group (UECG). Am J Ind Med 1996;29:602-8.

42. Orthopaedic Trauma Association Committee for Coding and Classification. Fracture and dislocation compendium. J Orthop Trauma 1996;10(Suppl 1):16-30.

43. Engelberg R, Martin DP, Agel J, Swiontkowski MF. Musculoskeletal function assessment: reference values for patient and non-patient samples. J Orthop Res 1999;17:101-9. 